\title{
Aproveitar a vida, juventude e gravidez ${ }^{1}$
}

\author{
Helen Gonçalves \& Daniela Riva Knauth \\ Universidade Federal de Pelotas - UFPel \\ Universidade Federal do Rio Grande do Sul - UFRGS
}

RESUMO: Este artigo propõe demonstrar que a concepção de aproveitar a vida tem significados importantes no universo investigado. A expressão surgiu no contexto de uma pesquisa de abordagem qualitativa, realizada em Pelotas, durante os anos de 2001-2002, com 23 jovens de 18-19 anos que já tinham filho(s) e com 10 de suas mães. $\mathrm{O}$ objetivo inicial do estudo era compreender o contexto da gravidez na adolescência em jovens das camadas popular e média, pertencentes a um estudo de coorte de nascimento/1982. Durante o trabalho de campo, o conceito de aproveitar a vida ganhou grande destaque nas narrativas, ajudou a qualificar, classificar e, principalmente, justificar os comportamentos afetivo-sexuais juvenis. As análises demonstram que a juventude deve se posicionar na vida de uma forma proveitosa, endossando positivamente os seus valores sociais. A gravidez das jovens, para as mães, é vista como um dos efeitos da inconseqüência e da modernidade e, para as jovens da camada popular, como algo que estava previsto, favorecendo o menor controle parental. Para as jovens da camada média, a gravidez interrompe temporariamente ou inverte planos de trabalho e estudo, e afeta menos a sociabilidade das jovens, pois estas contam com maior estrutura econômica e familiar para seguir curtindo a vida.

PALAVRAS-CHAVE: adolescentes, juventude, etnografia, gravidez na adolescência, aproveitar a vida, estudo qualitativo. 
Leva-se muito tempo para ser jovem.

(Pablo Picasso)

\section{Introdução}

A avaliação social sobre o comportamento de um indivíduo no seu grupo faz parte das regras sociais que perpassam todas as idades. A idade da pessoa é um referencial sociocultural importante, reflete comportamentos comuns e significativos para a compreensão da sociedade. De um modo ou de outro, as apreciaçóes sociais sobre o comportamento estão relacionadas com as conseqüências que ele possa provocar. No que se refere especificamente aos jovens, parte da bibliografia socioantropológica tem demonstrado que a juventude atual possui um valor simbólico, um estilo de vida identificado ao consumo do bem viver no Ocidente moderno - logo, pode ser consumida por outras idades e fases de vida (Groppo, 2000; Heilborn et al., 2002). Essa valorização da juventude realça a descronologização das fases de vida, relacionada às mudanças de eventos demográficos (Debert, 1998), e pode enfatizar e desvincular, em certa medida, a juventude/adolescência de alguns conteúdos rebeldes ou disfuncionais.

Os jovens "têm a vida pela frente", "devem aproveitá-la", "são novos", "há tempo para mudar e aprender a ter limites" são falas abrangentes e significantes do contexto juvenil. A coexistência entre a idéia de juventude valorizada e aquela das atitudes criticáveis (pela imaturidade e inconsequiência) ressalta como são alguns comportamentos absorvidos e adequados a cada contexto e tempo. As imagens, as representações, as percepçôes e os preconceitos do que é ser jovem ou adolescente, ou das expectativas da juventude, podem ser encontradas em expressōes de uso popular com significados múltiplos e exemplares para várias dis- 
cussões. No presente artigo, a idéia de aproveitar a vida serve-nos de ponto de referência para entender percepçôes e conceitos sobre a gravidez juvenil (antes dos 20 anos). Foram as jovens que engravidaram e suas mães que ressaltaram o valor dessa idéia a partir da juventude.

Sabe-se que a gravidez na adolescência (10-20 anos incompletos) tem sido veiculada como um problema social e de saúde pública (WHO, 2001). As referências ao evento estão acompanhadas de adjetivos, do tipo "precoce" e "indesejada", presentes nas visões biomédicas, ressaltando o comportamento, as conseqüências sociais e biológicas negativas dos comportamentos afetivo-sexuais dos adolescentes e jovens.

\section{Os universos investigados}

Em 2001-2002, por meio do Sistema de Informações de Nascidos Vivos, foi possível identificar jovens pertencentes ao estudo de coorte de 1982, em Pelotas-RS (Victora et al., 2003), que já tiveram filhos até os 19 anos. Após a identificação de 446 jovens que engravidaram, teve início um estudo etnográfico, com um universo de 26 jovens com filho(s), selecionadas por serem moradoras de bairros populares (13 jovens) e de camada média (10 jovens), localizados em setores censitários onde outros jovens sem filhos são também estudados. Os objetivos se propunham a entender se (e como) a gravidez afetaria, nessa etapa da vida, as trajetórias afetivo-sexuais, de trabalho e escolares das jovens. Do universo estudado, três jovens dificultaram os encontros no decorrer do trabalho de campo, não sendo possível desenvolver com elas um trabalho mais aprofundado - o material de análise não levou em consideração seus depoimentos. Além das 23 jovens com filho(s) que compunham o universo final, foram entrevistadas 10 mães. Optou-se por incorporar o ponto de vista dos familiares nas análises para a compreensão dos con- 
Helen Gonçalves \& Daniela Riva Knauth. Aproveitar a vida...

flitos geracionais relativos à sexualidade e à vida juvenil. As entrevistas foram autorizadas pelas jovens e por suas mães, e foram gravadas e transcritas respeitando o sigilo (nomes e informações). O projeto foi aprovado pelo Comitê de Ética da Universidade.

\section{O que é ser jovem?}

Uma frase que, apesar das variaçōes, surgia repetidas vezes nas conversas com as jovens e suas mães era "ser jovem é aproveitar a vida!". Investigar o que era esse aproveitar tornou-se fundamental para abarcar parte dos objetivos do estudo e para entender o que era a juventude segundo o universo pesquisado. Explorar os significados da referida expressão trouxe alguns esclarecimentos. Para as jovens, é a partir da juventude e em relação a essa fase que o verbo aproveitar toma de empréstimo certa conotação sexual/sensual e temporal, embora outras formas de uso sejam aplicadas concomitantemente. Aproveitar a vida, em sua forma usual e corriqueira, significa inicialmente sair, namorar, ficar, divertir-se, paquerar, dançar e curtir. Para as mães e as jovens, é ainda desfrutar a vitalidade dos anos, a sensualidade dos corpos, dos olhares e a sedução nem o corpo nem o trabalho de sedução precisam de muitos artifícios, pois faz parte da própria juventudelmocidadeladolescência ser atraente, sedutor em certa medida.

Além dessas possibilidades, o verbo e a expressão aproveitar podem ser empregados com outros significados, tais como usar (consumir), investir (em si ou em algo) e tirar vantagem de uma situação (emprego, ficar, beijo) ou de alguém (por exemplo, pela esperteza). São referências comuns ao aproveitar segundo o jeitinho brasileiro. Saber aproveitar a vida é reconhecer limites sociais e familiares, saber escolher até mesmo os parceiros, posicionar-se de modo mais aberto para o moderno e atual. 
Sendo assim, a conotação sensual e temporal focalizada na juventude se destaca justamente por ser um tempo apropriado para aproveitar a vida com corpo (ativo, saudável) e/ou mente aberta. Portanto, ser ou estar jovem pressupõe inicialmente uma forma de se colocar diante das situações e dos acontecimentos, diferente de outras etapas do ciclo da vida. Ser indica comportamento, aparência e idade. Estar pode ser mais do que ser, independe das idades: é estar com, ter espírito jovem - preservando a juventude, a leveza, o humor e a simplicidade com o avanço do tempo. Nesse sentido, o que está inscrito na idéia de aproveitar a vida é relevante para entender o processo de estar vivendo uma dada condição na juventude (ser nela) e de olhar para ela.

Há marcadores sociais importantes que definem espaços de sociabilidade e comportamentos. Em Pelotas, onde as jovens sempre moraram, a primeira quinzena de vida é um marco culturalmente importante para que o processo social de permissóes para namorar e sair à noite se consolide - quando, na prática, o aproveitar ganha os sentidos apontados anteriormente. Embora a idade etária possa ser questionada, é ao redor dos 15 anos que o reconhecimento familiar do aprendizado social, amadurecimento emocional e desenvolvimento corporal se manifesta, mais fortemente para as meninas, como a concordância dos pais com a ampliação dos locais, amigos e formas de lazer relacionados a elas. Esse processo dá continuidade e sentido a um ciclo mais amplo da vida e da sociedade, reproduzindo e reforçando mecanismos familiares de construção do indivíduo, além de trazer consigo a preocupação parental de orientar e limitar as atuações dos filhos (Duarte, 1986; Parker, 1991; Heilborn, 1994).

Entre jovens e mães, é comum o relato de uma sexualidade "à flor da pele" quando, em "plena juventude", começam a sair à noite. Segundo as mães, é nesse momento que a família teme a ultrapassagem do limite entre o exercício sexual e a promiscuidade, haja vista a necessidade de impor limites e controles conforme as situaçôes se apresentam. O poder 
Helen Gonçalves \& Daniela Riva Knauth. Aproveitar a vida...

coercitivo dos familiares tem forte relação com a necessidade de organizar e manter, estrutural e moralmente, às idades "adequadas", trabalho, casamento, filhos, responsabilidade e prioridade em relações e participações na sociedade. Portanto, no contexto mais amplo, o conteúdo do que se deve aproveitar na juventude também está inserido na própria discussão gerada nos meios público e científico sobre a precocidade da gravidez na adolescência, isto é, quando ela não deveria acontecer, quando os jovens precisariam ter "cuidados", ter "evitado" - o que reforça a idéia de imaturos, impulsivos. Tudo é crítica e aponta para a noção de inconseqüência própria da juventude se não traz à discussão a educação sexual na família.

Se aproveitar a juventude é também testar fronteiras valorativas e morais, que na atualidade estão mais fluidas, então, a gravidez adolescente enfatiza o lado oposto, de vinculação com compromissos: filho, companheiro, casa e cônjuge. Essa é uma forma com que se pode olhar para a gravidez diante de algumas concepções dissipadas de como ser nessa fase do ciclo da vida. $\mathrm{O}$ momento de rompimento criticado e moralizado está, em parte, aliado às qualidades positivas da vida juvenil.

Um pano de fundo mais abrangente e que faz diferença nas concepções e nos modos de articular idéias sobre os jovens, a gravidez e a passagem para a vida adulta é o contexto sociocultural e valorativo onde vivem. Por exemplo, retomando a distinção por camadas sociais, nas classes populares, a gravidez na juventude/adolescência é mais visível e muitas vezes parece menos angustiante para a família do que para as de camada média/alta. Essa visão diferenciada, associada aos dados demográficos (maiores índices de fecundidade), e a argumentação biomédica de que é um problema de saúde pública corroboram hoje para uma visão negativa da gravidez na adolescência - há décadas ela não era um problema. Ambos os argumentos não consideram como os valores sobre a juventude podem estar relacionados à própria gravidez na adolescência. 
Se a juventude deve ser aproveitada, então o jovem não deve assumir "compromissos" como gastos com filhos, aluguel, deveres com marido/ esposa, emprego, contas ou dívidas. Para a maioria das mães, idealmente, as filhas devem tentar perseguir outros objetivos - as aspiraçōes incluem maior formação escolar e emprego fixo. Mas tal idéia não exclui os ensinamentos domésticos (lavar, cozinhar, arrumar casa, cuidar de criança) como parte importante da formação feminina, vinculados a papéis mais tradicionais. Todavia, quando a jovem está, segundo a família, aproveitando mais do que "deveria" e a gravidez acontece nesse período, esta é avaliada como um evento que deu "um rumo" melhor à vida, pois a presença de um filho impóe a necessidade de uma nova conduta moral ("ela sossegou, se ajeitou"). Em geral, essas afirmativas são mais comuns depois que o pai do filho "assume" tanto a relação com a jovem como as despesas com o filho, ou quando a jovem realmente diminui o ritmo de suas saídas e namoros. Nesse sentido, por um lado, se a gravidez juvenil rompe com alguns projetos familiares, por outro, ela dá continuidade a eles, muitas vezes antes do desejado/previsto. Torná-la pública é fonte de preocupação moral, não implicando sempre tristeza ou decepção familiar. Lidar, por meio da gravidez, com as críticas morais que unem idade e sexualidade traz outro ponto importante: a visão que se estabelece ou prevalece dos jovens diante da fase adulta. A vida adulta é vista como um período menos divertido, de compromissos com trabalho e família. É uma fase em que se dá início ao projeto constante de ascensão e independência (social, material e psicológica), por isso a sociabilidade seria, segundo elas, menos interessante que a juvenil - é um período menos individualizado.

Como as normas de comportamento social e sexual são desiguais, as mulheres criam estratégias para superá-las e garantem sua atuação. Segundo as jovens, o discurso familiar sobre as diferenças entre o que homens e mulheres podem juntos ou separados prevalece como 
Helen Gonçalves \& Daniela Riva Knauth. Aproveitar a vida...

ensinamento mais enfático, principalmente no que poderá ocorrer a uma jovem caso ela engravide. Os comportamentos afetivo-sexuais e reprodutivos são os mais visados pelos familiares, porque podem trazer conseqüências posteriores ou criar laços de difícil dissolução. Ressalta-se que as expectativas associadas ao que as jovens podem ou devem fazer são distintas nas camadas médias e populares. Esses comportamentos também são focos de pesquisas em várias áreas da saúde, cujos resultados mostram um decréscimo na idade de iniciação sexual, um maior envolvimento sexual nos namoros ou "ficares" e o uso irregular (ou não uso) de preservativos e/ou contraceptivos.

Todavia, as expectativas, preocupações e idéias do que é ser jovem e de como usufruir a vida na juventude não descaracterizam um paradoxo: o da juventude como um período que se distingue pela curtição de sociabilidades e lazeres específicos e cujas regras sociais sinalizam que há um tempo finito, uma idade de se fazer, de ser de um jeito. Por um lado, exigem-se controle e sabedoria para experimentar/viver a juventude. Por outro, as cobranças se opõem diretamente a alguns mecanismos sociais que facilitam e estimulam as trocas, os erros e as experiências juvenis. Essa ambigüidade tende a comprometer as concepções mais positivas da juventude e a manter parte de sua conceituação negativa, como a de que a juventude/adolescência provoca instabilidades familiar, social e moral, que devem ser controladas para a continuidade dos valores familiares. A sexualidade das jovens é um caminho proveitoso para as avaliações juvenis e familiares.

A mulher e o lar formam uma equação constantemente questionada e, muitas vezes, são apenas parte do discurso juvenil moderno. A penetração de valores igualitários nas camadas sociais não atinge todas as jovens na mesma proporção. A preleção de que "com estudo está difícil, sem estudo está pior ainda" destaca a desigualdade e dificuldade de adotar outra atitude, que, por sua vez, pode demandar esforços também da 
família. Portanto, inicialmente nos discursos, um filho não é bem-vindo durante a adolescência, mas a gravidez poderá representar uma transição positiva de status para a família e a jovem, amenizando parte da obrigação da jovem com a família e da sua dependência familiar, potencializando novos rumos.

Embora a gravidez na adolescência/juventude também possa levar à interrupção (temporária ou não) dos estudos e à reprodução de papéis mais tradicionais de mãe-mulher, a exigência de maior escolaridade diante da menor oferta de trabalho faz que as famílias contatadas reforcem alguns de seus valores. Nas camadas médias, nas quais há uma vinculação e permanência mais longa dos filhos na casa dos pais por dependência econômica e/ou afetiva (Galland, 1997), a dependência material e residencial, devido à entrada postergada no mercado de trabalho, pressupõe que deva haver um adiamento da formação de uma nova família. Nesse sentido, a gravidez na adolescência/juventude passa a ser decorrente da liberdade atual e do modo como os jovens aproveitam a vida na modernidade. Para as jovens da camada popular, a gravidez vai de encontro das poucas chances históricas e socioculturais às quais estão subjugadas - faz parte de um conjunto de valores, cuja constituição de uma nova família pode se dar mais precocemente do que nas classes médias.

Estudos socioantropológicos demonstram que nas camadas populares há uma maior valorização da fase adulta, justamente por ela conformar um indivíduo menos dependente financeiramente dos pais (Heilborn et al., 2002; Groppo, 2000; Duarte, 1986). Trabalhando mais cedo, os filhos podem ajudar nos gastos diários e nas responsabilidades familiares, que os pais já não comportam sozinhos por várias razões. Se, no universo das jovens da camada popular, o aprendizado do trabalho doméstico também as orienta sobre como proceder no lar quando formarem suas famílias e, conseqüentemente, como incorporar e 
Helen Gonçalves \& Daniela Riva Knauth. Aproveitar a vida...

reproduzir uma grande parte do papel feminino no âmbito doméstico, as tensões entre os projetos de vida profissional e as possibilidades reais de ascensão juvenil estão também permeadas pelas alianças afetivo-sexuais, as quais se estabelecem geralmente durante a adolescência e/ou juventude. Ou seja, segundo suas visões, os conhecimentos adquiridos com a escolarização não garantem ascensão social e penetração no mercado de trabalho mais estável. Parte da descrença na escolarização, segundo elas, é explicada por greves, maus professores, péssima estrutura escolar e exemplos da comunidade. A assertiva de que "tá ruim pra todo mundo, até pra quem tem estudo" é mais corriqueira nesse universo, uma vez que justifica outras manobras de vida. Em muitos casos, não há tempo para que a conclusão do ensino fundamental e médio se efetue e, então, elas possam buscar um trabalho - a ajuda à família é cobrada no período anterior à conclusão do ensino, concomitantemente com as alianças afetivo-sexuais. Ao ponderar as repetências e/ou evasões, a "ajuda" por meio do trabalho fora do lar se faz ainda mais preeminente.

Se visualizarmos que o prolongamento da juventude está atrelado somente aos estudos e à inserção procrastinada no mercado de trabalho, de fato, nesse universo não há condições do prolongamento de a fase juvenil ocorrer. A gravidez seria uma das formas de ingresso feminino no mundo adulto, de maior liberdade, de ruptura com a própria adolescência, dependente e controlada socialmente. Além dos afazeres domésticos (Almeida, 2002), a maternidade (ou paternidade) é assinalada como uma forma de passagem da fase adolescente à vida adulta não pela capacidade biológica de fecundar e gestar, mas pela incorporação de responsabilidades e pelas implicações geradas por esse acontecimento na vida dos jovens (Arrilha, 1998; Cabral, 2002; Brandão, 2003). No entanto, na prática, há um grande espaço para que a tomada para si das responsabilidades e de outras características da vida adulta se dê de forma menos abrupta para as jovens: "Eu acho que falta mais um pouco de 
seriedade, encarar mais um pouco. Encarar os assuntos. Eu ainda estou meio, ainda me sinto meio... meio saindo da adolescência ainda. Eu não me sinto ainda adulta" (casada, mãe de uma menina, 19 anos, da camada popular).

Ao analisar as falas sobre a concepção de juventude, algumas especificidades do grupo entrevistado são percebidas. Em ambos universos sociais, especialmente as jovens que mencionavam a necessidade de saírem da casa dos pais, antes de imaginarem ou "planejarem"/“desejarem" a gravidez, demandavam às famílias uma liberdade vinculada muito mais à vida afetiva do que à total independência e autonomia dos pais por conquistas escolares/profissionais. A idéia de aproveitar a vida, ligada à sexualidade/emoção das relações e à liberdade do lazer, explica parcialmente os comportamentos das jovens à família.

Embora a gravidez seja um evento importante, para obter da família o reconhecimento de sua liberdade, são necessárias constantes confirmaçôes. Criam-se, então, um sentimento e um tempo dado pela família, bastante relativos e apropriados a cada caso, de adequação e de prolongamento de um aproveitar juvenil. Segundo Monteiro (1998, p. 146), "o que marca a passagem de uma fase para outra não é a celebração como rito, mas sim as experiências vividas no cotidiano, as exigências, os compromissos, as responsabilidades". Esse espaço faz que a família fique mais próxima, dando continuidade aos ensinamentos sobre os cuidados com a criança, com o companheiro (ou ex-companheiro) e com a vida social.

Quando ainda não tinham filhos, a independência financeira estava mais atrelada à satisfação imediata de consumo de produtos da moda. O trabalho doméstico podia servir, caso necessário, como moeda na negociação com os pais para que no final de semana pudessem sair com as(os) amigas(os). A idéia de rebeldia (na defesa do lazer) e de inconseqüência juvenil vem à tona e se confirma no momento em que os pais exemplificam que as filhas "acabaram" engravidando, logo, eles estavam 
certos ao aconselhá-las. Fica sempre a dúvida se a história não se repetirá. Isso também é válido quando as mães falam de suas vidas como exemplo para que as filhas não repitam o que consideraram um erro: "Eles são fruto da liberdade demais que eu tive, da irresponsabilidade que eu tinha - aí nasceram eles [...]. Carmem, ela não é uma filha ruim, a gente dava muito conselho a ela, ela não ouviu, ficou grávida”.

O sentimento de não surpresa da mãe para com a gravidez da filha vinha ao encontro das idéias modernas de juventude - isto é, natural que acontecesse com "os jovens de hoje", visto que "está tudo mudado". Não se constituiu em uma real surpresa, mesmo que ela tenha sido ventilada nos primeiros contatos do trabalho de campo como algo inesperado.

\section{Manter ou prolongar a juventude}

Em relação ao período posterior à gravidez, houve alongamento do sentimento de ser jovem nos casos em que a família, mais prontamente, possibilitou que a jovem retomasse parte de seu lazer, ajudando-a a cuidar da criança. Tendo em mente que há exceções e que muitas jovens e suas famílias não fazem uma relação direta do fim da adolescência com a gravidez, os pais corroboram para a manutenção de um sentimento e prática juvenil (se possível resumir assim), permitindo uma continuação da adolescência na gravidez e na maternidade - fato que ocorreu mais visivelmente com 10 jovens. Nesses casos, uma porção adolescente é mantida e uma mais adulta é cobrada quando a jovem dá sinais de certo retrocesso no processo de se tornar adulta. A passagem para a vida adulta em jovens adolescentes que engravidaram não é tão nítida, principalmente quando o filho é cuidado pela família e acaba por se tornar seu "meioirmão" (Monteiro, 1999). Portanto, o alongamento pode ser relativizado de acordo com a idéia de juventude e com o comportamento das moças. 
Revista de Antropologia, São Paulo, USP, 2006, v. 49 no 2.

No entanto, aquelas jovens que tiveram mais de um filho até os 19 anos, todas da camada popular, têm menos regalias e apoio familiar, principalmente se a segunda gravidez ocorreu fora de uma união estável, com poucas condições econômicas e apesar dos avisos da família. Tal fato é avaliado como uma falta de cabeça, isto é, não se deve ter outras expectativas com essa jovem.

No contexto social das camadas médias (com predominância de valores mais individualistas), a gravidez é pensada como muito precoce no sentido de deslocada da idade e do momento de vida certo. Ela ocorre justamente em um período em que há mais o que fazer por si e menos o que se responsabilizar pelo(s) outro(s). Poder-se-ia pensar que, por ser assim, na concepção de curtir a vida, a gravidez adolescente é vista como uma forma de abreviar a juventude. Porém, em um nível, ela fortalece uma dada aliança afetiva e material familiar, que dá suporte à jovem - de acordo com as condiçóes materiais e estruturais - para seguir com os projetos de estudo, trabalho e sociabilidade, embora pontuando sempre a necessidade de se responsabilizar pelo(a) filho(a). As jovens que não coabitam com o pai da criança encontram mais facilidades e apoio familiar para deixar seus filhos sob os cuidados de parentes enquanto saem com amigos para lazer. Por sua vez, elas demonstram que, além de se divertir, querem retornar ao mercado matrimonial e formar uma aliança afetivo-sexual com alguém "que (desta vez) dê certo". Quando não encontram apoio familiar, geralmente em situações de conflito, acionam convenientemente seus direitos como adulta-mãe-mulher - ganhos com a maternidade, mas que procuram não ativar em outros momentos.

Com as moças da camada média, o sentimento de que deveriam aproveitar a vida se alonga por mais tempo do que para as jovens da camada popular, visto que as condiçōes materiais já estão de algum modo garantidas. Aquelas buscam também uma identificação feminina mais 
Helen Gonçalves \& Daniela Riva Knauth. Aproveitar a vida...

restrita ao casal e ao lar, tendem a se limitar menos ao papel de mães e esposas, mas não deixam de pensar e fazer algo por seus estudos e por um futuro profissional, embora com certa restrição.

No universo popular, o sentimento de que a juventude deve ser desfrutada, ainda que semelhante ao das camadas médias, apresenta algumas diferenciações. Essas estão postas na forma como a família articula as responsabilidades da jovem advindas com a maternidade. Embora com exceções, as jovens desse universo tendem a ser mais cobradas pelos pais e assumem os papéis femininos restritos ao lar e ao filho, sobretudo se coabitam com o pai do filho ou com um novo parceiro: "a gente queria aproveitar mas, como veio filho, a gente tem que assumir as conseqüências". Elas se sentem mais presas à maternidade (às atividades respectivas) e ficam cada vez mais restritas ao âmbito do lar ou do bairro.

O fato de 16 jovens (das 23 entrevistadas) de ambos universos sociais morarem atualmente com algum familiar do pai da criança ou dela não só as coloca em situação de dependência familiar, mas permite aos pais dela um convívio maior com o jovem e um aprendizado do que este é atualmente. Se na prática moderna a redução do poder das idades está coligada à crescente valorização da juventude, questiona-se se esse comportamento também não estaria sendo influenciado pela permanência cada vez mais alongada dos jovens na casa dos pais. $\mathrm{O}$ que permitiria, em caso afirmativo, o maior consumo do que a juventude representa, ou seja, como ela pode ser aproveitada em outras fases do ciclo da vida.

Todavia, é importante ater-se que o aproveitar fala principalmente de uma representação sensual, sexual e valorizada, de experimentação de novas relaçôes, que se coadunam com uma noção mais moderna da juventude. Também diz muito sobre as fronteiras valorativas e morais que um jovem deve ou pode transpor para se constituir como indivíduo, para se separar de sua família e construir suas particularidades. Ao unir as concepções de juventude e a forma de aproveitar a vida, percebe-se 
muito sobre o modo como alguns familiares se colocam diante dos valores modernos atuais, também em relação à gravidez de uma filha jovem, cuja sexualidade foi publicada socialmente pela barriga.

\section{Considerações finais}

O espaço de experimentação e de valorização social que é dado de modo geral à juventude, percebido por meio de expressões como aproveitar a vida, ressalta as associações entre práticas e valores alocados no modo de vida jovem. Se existem representações e percepções sociais da juventude vinculadas às conceituações de um período difícil, conflituoso e preocupante, há ainda as que destacam a juventude como uma filosofia de vida para outras fases do ciclo da vida. Comportamentos juvenis que rompem uma trajetória e expectativa futura padrão são facilmente localizáveis nos programas de saúde e na literatura sobre adolescência e juventude como qualificaçóes pouco valorizadas. Tais juízos corroboram ainda para que o adjetivo de "epidemia" social, utilizado para a gravidez na adolescência, seja usado amplamente por trabalhos que não relativizam as vivências da condição juvenil nos universos sociais e, por conseguinte, a pluralidade da idéia de juventude nesses meios.

A gravidez na adolescência/juventude é um bom exemplo para exercitar os modelos juvenis de vida valorizados na modernidade e as definiçôes presentes de saúde e futuro. As concepções do que é ser jovem estão baseadas na construção histórica e sociocultural, e no modo como os jovens/adolescentes devem aproveitar a vida. Ressalta-se a existência de um aproveitar amplamente idealizado - como a entrada no mercado de trabalho, a escolarização ascendente e a posterior união -, porém nem sempre os estilos e modos juvenis de viver podem concordar com tal padrão e valorizá-lo. A própria gravidez torna-se um contraponto e um 
reforço negativo às idéias vigentes de uma vida que deve ser aproveitada, curtida no sentido com que as jovens associam primeiramente. Ao se considerar que há uma tensão entre aproveitar a vida e se preocupar com o futuro, deve-se ater como esse conflito se expressa e está implícito em muitos dos comportamentos e valores juvenis e familiares.

\section{Nota}

1 Este estudo é financiado pelas instituiçóes Wellcome Trust (Inglaterra) e Programa Nacional de Núcleos de Excelência (PRONEX) e pelo Ministério da Saúde (Brasil). As fases iniciais do estudo de coorte foram financiadas por International Development Research Center, Organização Mundial da Saúde e Overseas Development Administration (Reino Unido). O estudo também contou com o programa de bolsas da Capes.

\section{Bibliografia}

ALMEIDA, $\mathrm{M}$. 2002

Treze meninas e suas histórias... (um estudo sobre gravidez adolescente), XIII Encontro da Associação Brasileira de Estudos Populacionais, nov 4-8, Minas Gerais, Brasil.

ALVIM, R. \& PAIM, E.

2000

"Os jovens suburbanos e a mídia: conceitos e preconceitos", in ALVIM, R. \& GOUVEIA, P. (orgs.), Juventude anos 90: conceitos, imagens e contextos, Rio de Janeiro, Contra Capa Livraria, pp.13-33.

ARRILHA, M.

1998

"Homens: entre a 'zoeira' e a 'responsabilidade", in ARRILHA, M.; RIDENTI, S.; MEDRADO, B. (orgs.), Homens e masculinidades. Outras Palavras, São Paulo, ECOS/Editora 34, pp. 51-77. 
Revista de Antropologia, São Paulo, USP, 2006, v. 49 no 2.

BRANDÃO, E.

2003

Individuação e vínculo familiar em camadas médias: um olhar através da gravidez na adolescência, tese, IMS/RJ.

CABRAL, C.

2002

Vicissitudes da gravidez na adolescência entre jovens das camadas populares do Rio de Janeiro, dissertação, IMS/RJ.

CASTRO, M. G.; ABRAMOVAY, M.; RUA, M. G.; ANDRADE, E.

2001 Cultivando vida, desarmando violências: experiências em educação, cultura, lazer, esporte e cidadania com jovens em situação de pobreza, Brasília, Unesco.

CRUZ NETO, O.; MOREIRA, M. R.; SUCENA, L.

2001

Nem soldados nem inocentes: juventude e tráfico de drogas no Rio de Janeiro, Rio de Janeiro, Fiocruz.

DAYERELL, J. \& CARRANO, P.

2003

Jovens no Brasil: dificeis travessias de fim de século e promessas de um outro mundo. (Disponível em http://www.uff.br/obsjovem/ - acessado em 2/3/2003).)

DEBERT, G.

1998

"A antropologia e o estudo dos grupos e das categorias de idade", in LINS DE BARROS, M. (org.), Velhice ou terceira idade?, Rio de Janeiro, Fundação Getúlio Vargas, pp. 49-68.

DUARTE, L. F.

1986

Da vida nervosa das classes trabalhadoras urbanas, Rio de Janeiro, Jorge Zahar.

GALLAND, O.

1997 Sociologie de la jeunesse, Paris, Armand Colin.

GREGORI, M. F. (org.)

2000 Desenhos familiares. Pesquisa sobre família de crianças e adolescentes em situação de rua, Brasília, Alegro/Unesco/Fundação BankBoston. 
Helen Gonçalves \& Daniela Riva Knauth. Aproveitar a vida...

GROPPO, L.

2000

Juventude. Ensaios sobre sociologia e história das juventudes modernas, Rio de Janeiro, Difel.

HEILBORN, M. L.

1994 "De que gênero estamos falando?", Sexualidade, Gênero e Sociedade, Rio de Janeiro, vol. 1(2): 1-8.

HEILBORN, M. L.; SALEM, T.; BOZON, M.; AQUINO, E.; KANUTH, D. R. et al. 2002

"Aproximações sócio-antropológicas sobre gravidez na adolescência", Horizontes Antropológicos, Porto Alegre, vol. 8: 13-45.

MACHADO, E.

2000

"Retratos de juventude: imagens de juventude e violência no Rio de Janeiro", in ALVIM, R. \& GOUVEIA, P. (orgs.), Juventude anos 90: conceitos, imagens e contextos, Rio de Janeiro, Contra Capa Livraria, pp. 35-58.

MINAYO, M. C.; ASSIS, S.; SOUZA, E.; NJAINE, K.; DESLANDES S. F.; SILVA, C. M. et al.

1999 Fala galera: juventude, violência e cidadania, Rio de Janeiro, Garamond.

MONTEIRO, S.

1998 "Um estudo de rituais femininos em camadas de baixa renda", in MONTEIRO, T., Brasil. Norte e Nordeste. Estudos em Ciências Sociais, ANPOCS, InterAmerican Foundation, pp. 141-85.

1999 "Gênero, sexualidade e juventude numa favela carioca", in HEILBORN, M. L. (org.), Sexualidade: o olhar das ciências sociais, Rio de Janeiro, Jorge Zahar, pp. $117-45$.

PARKER, R. 1991

Corpos, prazeres e paixões. A cultura sexual no Brasil contemporâneo, São Paulo, Best Seller.

PERALVA, A. T.

1997

"O jovem como modelo cultural", Revista Brasileira de Educação, São Paulo, ANPED, no 5/6, pp. 15-24. 
SPOSITO, M. (org.)

2000

Considerações em torno do conhecimento sobre juventude na área da educação. Juventude e escolarização - estado do conhecimento, São Paulo, Ação Educativa.

VICTORA, C. G.; BARROS, F. C.; LIMA, R. C.; BEHAGUE, D. P.; GONÇALVES, H.; HORTA, B. L. et al.

2003 "The Pelotas Birth Cohort Study, Rio Grande do Sul, Brazil, 1982-2001", Caderno de Saúde Pública, vol. 19(5): 1.241-56.

WHO (World Health Organization)

2001

Sexual Relations Among Young People in Developing Countries: Evidence from WHO Case Studies, Geneva.

ABSTRACT: This manuscript demonstrates how important is the concept of enjoying life for the subjects studied. It was part of a qualitative study carried out in Pelotas during 2001-2002, including 23 adolescent mothers aged 18-19 years, and 10 of their mothers. The aim of the study was to understand the context of adolescent pregnancy among youngsters belonging to poor or medium socioeconomic level families, who are part of a birth cohort study/1982. During the field work, the concept of enjoying life was highlighted in the narratives. This concept helped qualifying, classifying, and justifying youth's behavior. The analyses show that the youngsters should live in an enjoyable way of living, acting positively or negatively according to the context and to the social values. Pregnancy is seen as a consequence of this behavior, after transposing socio-cultural limits in adolescence. Therefore, enjoying life highlights how do they feel, and explains why some behaviors are more criticized in this period of life course.

KEY-WORDS: qualitative study, enjoying life, ethnography, adolescent, adolescent pregnancy, young. 